Revista Pax Domini é licenciada sob

uma Licença Creative Commons.

\title{
A INFLUÊNCIA DA INTOLERÂNCIA RELIGIOSA PELOS ESCRITOS DE LINHA OFICIAL PRESENTES NA BÍBLIA
}

COSTA JÚNIOR, Belmiro Medeiros da ${ }^{1}$ OLIVEIRA, Liliane Costa de ${ }^{2}$ RIBEIRO, Reyth da Cunha ${ }^{3}$

\begin{abstract}
RESUMO
A Bíblia foi escrita a partir de duas linhas conflitantes, a saber, as linhas oficial e popular, que se contradizem teológica e ideologicamente, sendo a Bíblia na verdade, um intenso debate teológico entre grupos com interesses diferentes. Sendo assim, neste trabalho se discute como os escritos oficiais podem influenciar para a intolerância religiosa, já que os mesmos (escritos oficiais) refletem os interesses principalmente do templo e do palácio, defendendo privilégios e gerando intolerância e exclusão. Os escritos oficiais também são os mais percebidos nos textos sagrados, e os próprios textos sagrados são reconhecidos hoje como autoridade e inspirados, sendo reproduzidos no meio cristão e legitimando atitudes de intolerância religiosa. Para isso, faz-se um estudo de caso no livro de Josué que trata sobre a entrada do povo judeu de forma violenta em Canaã, já que a descrição da tomada da terra de Canaã, escrita em Josué pode ter refletido a época do reinado de Davi para legitimar em nome de Deus uma reivindicação de território e de domínio. A autoridade bíblica precisa ser entendida e repensada para que este e outros textos de violência e exclusão sejam lidos de forma crítica e libertadora, gerando assim, espiritualidade, amor, solidariedade e respeito diante das diversidades religiosas.
\end{abstract}

\section{Palavras-chave: Intolerância religiosa. Influência. Bíblia. Escrito oficial. Livro de Josué}

\begin{abstract}
The Bible was written from two conflicting lines, namely the official and popular lines that contradict theological and ideological, the Bible being actually an intense theological debate between groups with different interests. Thus, this work discusses how the official writings can influence to religious intolerance, as the same (official written) mainly reflect the interests of the temple and the palace, defending privileges and generating intolerance and exclusion. The official writings are also the most perceived in the sacred texts and their own sacred texts are recognized today as authoritative and inspired, and played in the Christian and legitimizing religious attitudes of intolerance. For this, it is a case study in the book of Joshua which deals with the entry of the Jewish people violently in Canaan, since the description of the taking of the land of Canaan, written in Joshua may have reflected the era of the reign of David to justify in the name of God a claim of territory and domain. The biblical authority needs to be understood and rethought so that this and other of violence and exclusion texts are read in a critical and liberating way, generating, spirituality, love, solidarity and respect in the face of religious diversity.
\end{abstract}

Keywords: religious intolerance. Influence. Bible. Official writing. Book of Joshua.

\footnotetext{
${ }^{1}$ Mestre em Teologia pela Faculdades Escola Superior de Teologia (EST); Especialista em Magistério do Ensino Superior pela Faculdade Boas Novas (FBN); Bacharel em Ciências Teológicas pela Faculdade Boas Novas (FBN); Pesquisador da temática de Religião no Núcleo de Estudos e Pesquisa em Religião, Cultura e Imaginário - OIKOUMENE; Professor na Faculdade Boas Novas (FBN); belmiromcjunior@gmail.com

${ }^{2}$ Mestre em Sociologia pela Universidade Federal do Amazonas (UFAM); Graduada em Ciências Sociais pela Universidade Federal do Amazonas (UFAM); Graduada em Teologia pela Faculdade Boas Novas (FBN); Pesquisadora da temática de Religião no Núcleo de Estudos e Pesquisa em Religião, Cultura e Imaginário - OIKOUMENE; Professora na Faculdade Boas Novas (FBN); lilioliveira123@yahoo.com.br

${ }^{3}$ Mestre em Teologia pela Faculdades EST (Escola Superior de Teologia); Especialista em Magistério do Ensino Superior pela Faculdade Boas Novas e Bacharel em Ciências Teológicas pela Faculdade Boas Novas (FBN); Licenciado em Ciências Sociais pela Universidade Luterana do Brasil (ULBRA); Graduando em Filosofia pela Universidade Federal do Amazonas (UFAM); Pesquisador da temática de Religião no Núcleo de Estudos e Pesquisa em Religião, Cultura e Imaginário OIKOUMENE; Professor na Faculdade Boas Novas. E-mail: reyth_ribeiro@ hotmail.com
}

Revista Pax Domini | Faculdade Boas Novas | vol. 1 | p. 143 - 157 | jul./dez. 2015 


\title{
INTRODUÇÃO
}

A Bíblia tem sido instrumentalizada tanto para promover a paz, o amor e a vida, como também para promover a guerra, a morte e a intolerância religiosa. O problema se dá pelo fato de a Bíblia, em suas histórias apresentar duas faces do Deus Javé. Ele é tanto um Deus que incita a violência, a guerra, a intolerância e a exclusão, como também é um Deus que promove a paz, a justiça, a tolerância e a vida.

Assim, este artigo mostra que a Bíblia foi escrita a partir de duas linhas conflitantes teológica e ideologicamente. Estas linhas seriam a oficial e a popular. A primeira defende privilégios, gerando exclusão, é a linha que intenta defender as atitudes do palácio e do templo. Já a segunda é a linha que reflete a resistência do povo pobre, oprimido e explorado. Assim, se entende que os escritos de linha oficial, pela sua teologia excludente, acaba influenciando à atitudes de intolerância religiosa.

Este trabalho está dividido em duas partes. Na primeira explica a intolerância religiosa, esclarecendo em seguida sua relação com a Bíblia. Traz ainda uma explicação sobre como se dá a existência das linhas oficial e popular nos textos bíblicos. A segunda parte faz um estudo de caso no livro de Josué desconstruindo a ideia de violência e intolerância presentes no texto.

\section{A INTOLERÂNCIA E A BÍBLIA}

Para explicar o que é intolerância religiosa, lança-se mão do conceito de intolerância expresso na cartilha sobre diversidade religiosa e direitos humanos:

\begin{abstract}
A intolerância religiosa é um conjunto de ideologias e atitudes ofensivas, discriminatórias e de desrespeito às diferentes crenças e práticas religiosas ou a quem não segue uma religião. Sendo como um crime de ódio que fere a liberdade, a dignidade humana e a própria democracia, a intolerância religiosa costuma ser caracterizada pela ofensa, discriminação, perseguição, ataques, desqualificação e destruição de locais e símbolos sagrados, roupas e objetos ritualísticos, imagens, divindades, hábitos e práticas religiosas. Em casos extremos, há atos de violência física e que atentam à vida de um determinado grupo que tem em comum determinada crença. A intolerância religiosa, com frequência está vinculada ao racismo, sendo um desrespeito aos Direitos Humanos. E é crime, previsto no Código Penal Brasileiro. (BRASIL, 2013, p. 9-10).
\end{abstract}

É fato que a intolerância religiosa no Brasil não é manifesta por guerras e mortes como em alguns países, porém, se dá pela ofensa, discriminação, perseguição, ataques, desqualificação e

Revista Pax Domini | Faculdade Boas Novas | vol. 1 | p. 143 - 157 | jul./dez. 2015 
destruição de locais e símbolos sagrados. Estas atitudes ocorrem principalmente pelo discurso ideológico religioso. O qual acaba legitimando outras práticas, como a violência.

A Bíblia para alguns grupos cristãos tem sido instrumento de legitimação para tais práticas. Conforme Silva (2007, p. 13), o discurso religioso cristão, principalmente dos grupos que não estão engajados no diálogo religioso, continua fazendo uso das teses bíblicas que colocam o cristianismo como religião exclusiva demonizando todas as outras. Compreende-se assim, que o diferente, aquele que não professa a mesma fé, que não tem as mesmas experiências religiosas passa a ser combatido. O amor, a paz e o respeito transmitidos pela própria Bíblia passam a ser ofuscados por mensagens extraídas da mesma fonte que incitam a intolerância. Professar a mesma religião não pode ser prérequisito para a tolerância religiosa.

De que forma se apresenta a intolerância religiosa nos dias atuais? Apresenta-se na forma do discurso intolerante resultado da interpretação fundamentalista dos textos considerados sagrados pelos grupos. Apresenta-se através de programas de rádio e televisão e na divulgação de literatura que tem por objetivo demonizar práticas e ensinos de outros grupos religiosos. Apresenta-se através de violência física e invasões à locais de cultos. (SILVA, 2012, p.1196).

Pode-se dizer que a chave hermenêutica utilizada para uma leitura intolerante da Bíblia tem sido baseada na concepção de um Deus intolerante e violento, onde perícopes bíblicas de guerras e violências estimuladas por Javé são partes destas leituras. A interpretação fundamentalista, ou seja, a que procura interpretar tais textos ao pé da letra, pode acabar reproduzindo discursos de intolerância. É importante mudar tais princípios, pois a mesma Bíblia apresenta Javé como um Deus amoroso, misericordioso, pacífico e tolerante. É preciso resgatar tais textos que $\mathrm{O}$ apresentam assim.

\subsection{As duas linhas conflitantes}

A Bíblia não é um livro de história, mas de interpretação da mesma. Quando se estuda os textos bíblicos, na verdade não se estudam as histórias, mas as releituras das mesmas. Para entender isso, é importante entender também que os textos bíblicos não surgiram logo após os fatos históricos ocorrerem. "Antes do texto escrito, vêm experiências vividas pelas mais diferentes pessoas e em lugares variados. Todas essas experiências foram sendo contadas, recontadas durante muito tempo. Só então a memória virou texto.” (GASS, 2002, p. 43).

Um exemplo é o livro do Pentateuco. Suas histórias só foram escritas por tradições que datam

Revista Pax Domini | Faculdade Boas Novas | vol. 1 | p. 143 - 157 | jul./dez. 2015 
de 950 a 550 a.C., ${ }^{4}$ ou seja, os primeiros escritos datam 400 anos depois dos fatos terem ocorrido. Seria possível guardar todo o conteúdo dos fatos pela própria tradição oral com toda a fidelidade, mesmo depois de tanto tempo? Como confiar na objetividade histórica destes textos? Não há como preservar todos os fatos da história quando a mesma é preservada apenas pela tradição oral.

No Primeiro Testamento, temos sucessivas interpretações ou releituras da história, da ação de Deus junto a seu povo no passado. Cada releitura tem como objetivo principal atualizar a Palavra de Deus para um novo momento. As dificuldades já não são as mesmas do passado. Há outros problemas a serem enfrentados. O contexto é outro. Exige novas soluções. (GASS, 2002, p. 42).

A história assim era reutilizada, reelaborada e reaplicada no decorrer dos tempos bíblicos. Novos temas foram entrelaçados e novos relatos acrescentados, para ajudar as Escrituras a manterem-se vivas e a falar de modo significativo para uma nova geração numa nova situação histórica. Smith (2006, p. 35), ao falar sobre o assunto, vai dizer que a "história bíblica", representa a história nacional fundadora de Israel como refém das condições do presente do povo e de suas esperanças no futuro.

Se havia reelaborações nestas histórias, havia então intenções. Os autores que as escreveram, o fizeram visando algum propósito em suas comunidades, assim descreveram as histórias acrescentando suas intenções. Pixley (2004, p. 9), quando se referiu à busca do sentido dos fatos da história de Israel, disse que o sentido da história não é evidente na sua superfície. Para descobrir seu sentido é necessário explorar a profundidade dos eventos. Nos documentos deixados por qualquer história sempre existem interesses que ocultam o sentido dos acontecimentos. Nestas circunstâncias a busca do sentido toma, às vezes, características “detetivescas”. A história de Israel não está isenta destes problemas. Assim, uma das perguntas a ser feita aos textos bíblicos é: qual a intenção de quem escreveu o texto?

Desta forma, a Bíblia contém a produção teológica e ideológica de grupos e comunidades. Conforme Gass (2002, p. 32), o povo de Israel também viveu seus dramas, seus conflitos internos. Havia projetos em conflito. Essa tensão transparece nos escritos bíblicos. Este conflito ou confronto ocorre em toda história da Bíblia a partir de duas linhas fundamentais. Estas linhas são chamadas de oficial e popular. São linhas de interesses teológicos, econômicos e políticos distintos e que se defrontam. São as linhas conflitantes na Bíblia.

Gass (2002, p. 34-36) traz uma explicação sobre as duas linhas:

A linha oficial. A linha oficial será a linha que transmitirá os interesses dos palácios e do

${ }^{4}$ Aqui é apoiado os últimos estudos da alta Crítica ao Pentateuco, que datam a fonte Javista como a mais antiga (950 a.C) e a fonte Sacerdotal como a última (550 a.C).

Revista Pax Domini | Faculdade Boas Novas | vol. 1 | p. 143 - 157 | jul./dez. 2015 
templo. Defendendo privilégios e gerando exclusão. Reflete os interesses dos reis, da corte, do templo, do sacerdócio oficial e dos juízes vinculados aos reis, dos latifundiários e dos grandes comerciantes. Visam a uma política de escravidão, tributos, saques, trabalho forçado, exército forte e oneroso.

Esta mesma linha é excludente. Exclui, defende privilégios. E pior, legitima-os em nome de Deus. É dela que vêm as leis do puro e do impuro, da estrita observância da lei, da única raça eleita, da teologia da retribuição que afirmava que tudo é retribuição de Deus de acordo com a vida das pessoas. Segundo essa teologia, riqueza, saúde, família numerosa, honra, longa vida são bênçãos de Deus para os justos. Já pobreza, doença, esterilidade, desonra, morte prematura são castigos de Deus para os pecadores. É importante lembrar que o próprio Jesus nasceu pobre. É exatamente esta linha oficial, que este artigo defende como a linha que influencia as práticas de intolerância religiosa. Porém, convém falar ainda sobre a linha popular.

A linha popular. É a linha de resistência aos escritos oficiais com todos os seus interesses. Que resistiam ao sistema de escravidão, de tributos, saques e trabalhos forçados. É a sociedade tribal que defende as aldeias, o uso familiar da terra, os pequenos santuários rurais, o trabalho livre. Inclui pessoas e categorias excluídas como as mulheres, os pobres, os doentes, os deficientes e estrangeiros.

Abaixo está um quadro que apresenta as duas linhas contrastantes:

\begin{tabular}{|c|c|}
\hline Linha Oficial & Linha Popular \\
\hline $\begin{array}{l}\text { Afirma que Deus é favorável à opção pelo } \\
\text { reinado }(1 \mathrm{Sm} 9.15-16 ; 10.1) \text {. }\end{array}$ & $\begin{array}{l}\text { Afirma que Deus condena a opção pelo } \\
\text { reinado (1Sm } 8.1-18 ; 12.19) \text {. }\end{array}$ \\
\hline $\begin{array}{l}\text { Exclui os estrangeiros (Dt 2. 4; Ed } 9-10 \text {; } \\
\text { Ne 13). }\end{array}$ & $\begin{array}{l}\text { Inclui estrangeiros (Rt 1. 16-17; Is 56. 3; } \\
\text { Lc 10. 30-37; Jonas; At } 8-10 \text { ). }\end{array}$ \\
\hline É favorável ao templo (2Sm 7. 1-3; Ag 1). & $\begin{array}{l}\text { É crítica ao templo (2Sm 7. 4-7; Is 66. 1- } \\
\text { 2; Jr 7; 26; Am 9. 1-4; Mq 3. 12; Mc } 11 . \\
\text { 15-18; 13. 1-2). }\end{array}$ \\
\hline $\begin{array}{l}\text { Religião centrada em sacrifícios e ritos } \\
\text { externos (conferir somente títulos que } \\
\text { aparecem nos capítulos } 1 \text { a } 8 \text { de Levítico). }\end{array}$ & $\begin{array}{l}\text { Religião baseada na justiça e na } \\
\text { solidariedade (Is 1. 10-17; 58. 1-12; Os } 6 . \\
\text { 6; Am 5. 21-24; Mt 9. 13; 12.7). }\end{array}$ \\
\hline $\begin{array}{l}\text { Exclui mulheres, considerando-as impuras } \\
\text { e inferiores (Lv 12; 15. 19-30; Jo 8. 1-11. }\end{array}$ & $\begin{array}{l}\text { Incluem mulheres, valorizando sua beleza, } \\
\text { sua sabedoria, seu corpo, sua vida (Pv } 31 \text {. } \\
\text { 10-31; Rute; Judite; Ester; Cântico dos }\end{array}$ \\
\hline
\end{tabular}

Revista Pax Domini | Faculdade Boas Novas | vol. 1 | p. 143 - 157 | jul./dez. 2015 


\begin{tabular}{|c|c|}
\hline & $\begin{array}{l}\text { Cânticos. Também Jesus resgata a } \\
\text { dignidade das mulheres). }\end{array}$ \\
\hline $\begin{array}{l}\text { Condena os pobres e doentes como se } \\
\text { pobreza e doença fossem castigos de Deus } \\
\text { por seus pecados (no livro de Jó, seus } \\
\text { amigos representam a teologia oficial, a } \\
\text { teologia da retribuição. Como amostra, ler } \\
\text { os capítulos } 4 \text { e 5). }\end{array}$ & $\begin{array}{l}\text { Vem em defesa dos pobres e doentes, } \\
\text { apontando as verdadeiras causas da } \\
\text { pobreza (a figura de Jó representa a } \\
\text { teologia popular de resistência [Jó 24. 1- } \\
\text { 12; 31]. Jesus vem nesta mesma corrente } \\
\text { [Lc 13. 1-5; Jo 9. 1-3]). }\end{array}$ \\
\hline $\begin{array}{l}\text { Obriga à observância das leis de pureza } \\
\text { exterior (Mc 7. 1-5). }\end{array}$ & $\begin{array}{l}\text { Coloca no seu devido lugar os } \\
\text { mandamentos de Deus (Mc 7. 6-13) e } \\
\text { defende a pureza do coração, livre de } \\
\text { roubos e injustiças (Mc 7. 14-23). }\end{array}$ \\
\hline $\begin{array}{l}\text { Obriga à observância minuciosa da } \\
\text { tradição do sábado (Mt 12. 1-14). }\end{array}$ & $\begin{array}{l}\text { Coloca a vida acima da lei, cuja função é } \\
\text { estar a serviço das pessoas, e não o } \\
\text { contrário (Mt 12. 1-14). }\end{array}$ \\
\hline $\begin{array}{l}\text { Exige a circuncisão, a remoção do } \\
\text { prepúcio no órgão genital masculino (Gn } \\
\text { 17). }\end{array}$ & $\begin{array}{l}\text { Exige a circuncisão do coração, isto é, a } \\
\text { mudança de vida (Dt 10. 16; Jr 4. 4; Rm } 2 . \\
\text { 29). }\end{array}$ \\
\hline $\begin{array}{l}\text { Exclui pessoas com deficiências físicas } \\
\text { (Lv 21. 17-21; Dt 23. 2). }\end{array}$ & $\begin{array}{l}\text { Inclui as pessoas com deficiências (Is } 29 \text {. } \\
\text { 18-19; 35. 5-6; 56. 3-5; Mt 11. 4-5; At } 8 \text {. } \\
\text { 26-40). }\end{array}$ \\
\hline
\end{tabular}

Quadro 1: Linhas Oficial e Popular.

Fonte: GASS, 2002, p. 36.

O quadro acima mostra que estas duas linhas estão misturadas em toda a Bíblia. Em alguns momentos não é fácil saber qual seria a linha oficial e qual seria a linha popular. É preciso verificar as intenções do texto, a quem parece privilegiar, se o texto gera justiça ou exclusão. Assim também é preciso ter mais clareza quanto aos critérios de interpretação, pois a Bíblia pode ser usada tanto como instrumento de opressão e morte como também serve como instrumento de promoção e defesa da vida.

Existem na Bíblia muitos textos que estimulam à violência, exclusão, porém o que se afirma aqui, é que a maioria dos textos vêm dos escritos de linha oficial. A questão é que estes escritos são os mais percebidos nos textos bíblicos. Os próprios textos bíblicos são tidos como autoridade e Palavra de 
Deus, legitimando tais atos de intolerância religiosa.

Só o fato de saber que estes textos geram exclusão, já dá para entender o por que de se acusar os escritos oficiais como incentivadores à intolerância. Uma das categorias excluídas seria a dos estrangeiros que para os hebreus em sua maioria adoravam a outros deuses, pertenciam a outras religiões e assim, não poderiam conviver juntos em comunidade de forma pacífica, não faziam parte do "povo escolhido" por Deus.

O próprio relato de Abraão e Sara despedindo a escrava egípcia Agar e seu filho Ismael (Gn 21. 14) faz parte de escritos de linha oficial do período pós-exílico, onde houve a necessidade de um escrito que legitimasse a expulsão e o fim dos casamentos com mulheres estrangeiras (Ed 9 - 10; Ne 13). Esta foi uma das atitudes radicais para proteger a identidade do povo judeu. Não há como negar que foi uma atitude que gerou grande injustiça, principalmente contra as mulheres estrangeiras e seus filhos.

Conforme Dietrich (2013, p. 16), o processo de intolerância e violência começou no período da monarquia Judaica, com o movimento em direção ao monoteísmo, que aconteceu ou sob o patrocínio, ou em aliança com o poder político, e carrega em si um alto grau de violência e imposição, estando, na maior parte das vezes, associado a um projeto de dominação, tendo uma função importante na legitimação da dominação de um grupo sobre outros.

Este fato começou com o rei Davi, que para consolidar seu poder, levou a Arca de Javé que estava com as tribos de Benjamin e Efraim, para dentro das muralhas de Jerusalém (2Sm 6. 1-23). Conforme Gass (2011, p. 29) a Arca era sinal da presença do Deus libertador do êxodo nas aldeias do interior (Js 8. 33; Jz 20. 26-28; 1Sm 4. 3-4). Em vez de continuar ligada às tribos no interior, a Arca passou a ser vinculada diretamente ao rei, à monarquia na capital. Agora Davi e a monarquia davídica começaram a ser apresentados como representantes de Javé dos exércitos, o Deus da Arca. O culto a Javé passa a ser o culto oficial.

Davi passa a ser representante de Javé dos exércitos. Dietrich (2013, p. 17) mostra o visível vínculo entre a narrativa da luta entre Davi e Golias (1Sm 17. 1 - 18. 5) e a chamada narrativa da Arca (1 Sm 4. 1b - 7.1). A narrativa de $1 \mathrm{Sm} 5$ reporta que os filisteus depositaram a arca no templo de Dagon, "ao lado" de Dagon. O relato mostra que por duas vezes, os filisteus encontraram Dagon "caído com sua face para terra" (1Sm 5.3 -4). Em 1Sm 17. 49, o Golias cai diante de Davi da mesma forma como Dagon caiu diante da Arca. Mesmo diante da violência da pedra lançada sobre sua testa, o filisteu caiu para frente.

Revista Pax Domini | Faculdade Boas Novas | vol. 1 | p. 143 - 157 | jul./dez. 2015 
Isso é reforçado pelo fato de pouco antes deste desfecho os dois guerreiros terem se assumido como representantes de seus Deuses. Em 17.43, o filisteu "amaldiçoou Davi por seus Deuses", e, no verso 45, Davi responde ao filisteu, dizendo que o enfrenta "em nome de Javé dos Exércitos, o Deus das fileiras de Israel". Assim, diante de Davi, que fala em nome de Javé dos Exércitos, "Golias" cai da mesma maneira como Dagon caiu diante da arca de Javé dos Exércitos. (DIETRICH, 2013, p. 18).

Nota-se aqui que o fato de os dois entrarem em confronto representando deuses diferentes, já se apresenta nestes escritos oficiais a intolerância religiosa. Davi agora representando Deus, promoverá suas guerras em nome de Javé dos Exércitos contra outras nações e seus deuses.

Dietrich (2013, p. 23) diz ainda que foi no tempo das reformas políticas e religiosas realizadas pelo monarca Ezequias, que uma série de textos presentes no Pentateuco e outros livros históricos e dos profetas foram reelaborados, gravando nestes textos o rosto de um Javé oficial violento, excluidor, exclusivista, homogeneizador e intolerante. Ezequias promoveu reformas de intolerância.

O problema foi que estes líderes refletiram suas atitudes intolerantes nos textos bíblicos. Passaram a legitimar suas ações e reformas reutilizando e reelaborando a história do povo de Israel de forma que mostrassem que Deus estava com eles, estava mandando, ordenando, era sua vontade. Assim, o povo poderia segui-los e apoiá-los.

\section{UM ESTUDO DE CASO NO LIVRO DE JOSUÉ}

Esta parte falará sobre o livro de Josué, trazendo como proposta a desconstrução de uma interpretação baseada em uma visão geral e literal do livro, que conforme Dreher (1992) a visão do conjunto do livro parece insistir em apresentar a ideia de uma conquista global e unitária, porém, havendo uma aproximação aos detalhes do texto concluir-se-á que tal pretensão não se confirma. Por questão de espaço, não há a intensão de trabalhar esta parte de forma exaustiva ${ }^{5}$, pois o foco principal está em apontar os escritos de linha oficial presentes no livro.

A pesquisa ainda não se propõe apenas a desconstruir, mas apresentar uma reinterpretação do livro de forma que haja conscientização e libertação, de maneira a apresentar um Deus que caminha, defende e luta com seu povo para a promoção da justiça, para realizar e manter uma comunidade livre e justa. Este trabalho é consciente de que "a pergunta por origem e formação de Israel é das questões

\footnotetext{
${ }^{5}$ Para saber mais sobre os problemas no livro de Josué, é indicado o artigo do Dr. Carlos Arthur Dreher: Josué: ¿modelo de conquistador? Revista de Interpretación Bíblica Latinoamericana - Biblia: 500 años: ¿conquista o inclusión? n. 12. Disponível em: <http://www.claiweb.org/ribla/ribla1-13.html>.
}

Revista Pax Domini | Faculdade Boas Novas | vol. 1 | p. 143 - 157 | jul./dez. 2015 
mais complexas e polêmicas. Nela se exercitam diversas teorias com resultados significativamente divergentes." (SCHWANTES, 2008, p. 33). Sendo assim, concordando com Schwantes, a presente exposição não se arroga a pretensão de haver encontrado a solução, mas se une a leitura popular da Bíblia, propondo uma leitura libertadora.

No livro de Josué a tomada da terra se dá em duas etapas principais: conquista (caps. 2 - 12); e distribuição da terra (13 - 21) (SCHMIDT, 1994, p. 143). A primeira etapa (conquista) também pode ser dividida em três fases sucessivas: lutas e conquistas no território de Benjamin (Caps. 2; 6 - 8; 9); uma incursão ao sul (cap. 10); uma incursão ao norte (cap. 11) e assim o processo está concluído. A segunda etapa (distribuição da terra) igualmente pode ser dividida em três etapas: repartição dos territórios ocupados entre as tribos de Israel (caps. 13 - 19); discriminação das cidades de refúgio (cap. 20); e enumeração das cidades reservadas aos levitas. O livro encerra ainda com o retorno das tribos da Transjordânia e construção de um altar para as mesmas (cap. 22) e dois discursos de despedida de Josué (caps. 23, 24).

A partir da visão panorâmica do livro, a conclusão que se tem, é de que Israel, com suas doze tribos unidas, penetrou e conquistou Canaã por completo, tomando a terra de forma violenta, desterrando e matando seus antigos habitantes. Assim Deus escolheu uma nação e rejeitou outras e as expulsou violentamente porque tinham outra religião e outros deuses.

E aqui se apresentam alguns problemas morais do livro: primeiro, pode-se, com efeito, acreditar nas ordens de Javé para destruir completamente os habitantes do país? Se houver uma concordância desta interpretação baseada em uma visão geral deixando de lado um olhar mais aproximado nos detalhes do livro, até que ponto esta revelação de Javé estaria de acordo com a revelação que Cristo faz acerca do mesmo? Ou seja, Por que um Deus amoroso e misericordioso, preocupado em resgatar a humanidade, optaria em eliminá-la? Não há dúvidas de que isso trás confusão e dificuldade para compreendê-Lo.

Outro problema, é que uma interpretação equivocada do livro que tenha como conclusão a punição divina destes povos por causa de sua religião e seus deuses, pode levar à legitimação de atitudes de intolerância religiosa. Conforme Dreher (1992), tal tipo de interpretação admite ver em Josué um modelo de conquistador, dando oportunidade para que em qualquer momento esta leitura seja retomada para justificar desmandos genocidas. Não seria difícil imaginar a utilização do livro de Josué como legitimador tanto da escravidão negra incitada pela reconquista, quanto do massacre indígena no continente sul-americano.

Revista Pax Domini | Faculdade Boas Novas | vol. 1 | p. 143 - 157 | jul./dez. 2015 
O fato é que a história e a arqueologia dificilmente confirmam a versão da conquista da terra apresentada pelo livro de Josué (1 - 12). Conforme afirma Schmidt (1994, p. 23):

Este processo imigratório, propositalmente designado com a expressão neutra "tomada da terra" (A. Alt), dificilmente se caracterizou (ao contrário de Js 1 - 12) por atividades guerreiras onde todo o Israel, unido sob uma liderança comum, tivesse conquistado, passo a passo, todo o país. Tratou-se, antes, de um processo essencialmente pacífico, gradativo e, ao que parece, demorado de paulatina sedentarização.

Os próprios relatos das conquistas das cidades de Jericó e em seguida da cidade de Ai, não encontram apoio arqueológico, pois há comprovações de que estas duas cidades estavam destruídas muito antes da época dos fatos ocorridos no livro de Josué. A cidade de Ai, por exemplo, já era desde o $3^{\text {o }}$ milênio a.C., o que seu nome significa, um "monte de ruínas", sem habitação urbana (DONNER, 1997, p. 139).

Dreher (1992) apresenta não apenas contradições no próprio livro de Josué, mas também aponta o livro de Juízes como contra espelho do mesmo (Josué). Enquanto algumas passagens do livro dão a entender que toda a terra e todos os reis cananeus já estavam derrotados após a ocupação da terra (Js 11. 15-23; 21. 43-45), outras passagens no mesmo livro e no livro de Juízes vão mostrar outra realidade, de que os reis cananeus continuavam existindo (Js 13. 1-6, 13; 15. 63; 16. 10; 17. 11-13).

O livro de Juízes vai mostrar ainda que esta conquista ocorreu em um processo lento e difícil, apresentando um aglomerado de pequenas histórias e notas sobre a temática da tomada da terra, trazendo uma listagem de tribos israelitas e de cidades e territórios que as mesmas, no decorrer da tomada da terra não estiveram em condições de conquistar. Estas tribos são apresentadas isoladas e independentes, tentando ocupar suas terras, não há relato sobre as doze tribos unidas na conquista, até mesmo Josué já estava morto no tempo destas invasões (Jz 1.1). Alguns relatos de conquistas ocorridas sob a liderança de Josué (Js 15. 15-19; 10), são repetidos no livro de Juízes como que após a sua morte (Jz 1. 11-15; 1. 4-10).

Aqui já pode ocorrer a seguinte pergunta: se estes fatos não ocorreram como está no livro, como então interpretar, ou melhor, como ler o livro de Josué? Ceresko (1996, p. 99) traz a seguinte afirmação:

A "verdade" nessa parte da Bíblia que vai de Gênesis até Juízes não deve ser buscada mediante alguma tentativa de reconstruir "o que realmente aconteceu". Isso se comprovou uma tarefa impossível, a não ser que simplesmente se aceite o relato bíblico ao pé da letra. A verdade da

Revista Pax Domini | Faculdade Boas Novas | vol. 1 | p. 143 - 157 | jul./dez. 2015 
narrativa se encontra, antes, imaginando o contexto do qual surgiram essas narrativas, reconstruindo o processo pelo qual elas foram combinadas e recuperando a função que elas devem ter tido. É importante também discernir o tipo social, econômico, religioso e político do(s) grupo(s) em que esse processo e essas funções aconteceram.

O que se pode dizer a partir do texto acima, é que o livro de Josué não deve ser pensado apenas desde os fatos ocorridos no livro, ou seja, a tomada da terra por um Israel unido de forma global e rápida, mas também deve ser lido e pensando desde o contexto dos autores que escreveram a história contida no livro. É relevante fazer a seguinte pergunta: que interesse teria ou a quem interessa recontar a história da formação do povo de Israel em Canaã enfatizando uma conquista global de forma violenta?

Um dos pontos chaves para se chegar à resposta da pergunta acima é analisando as palavras de Donner (1997, p. 140) que diz:

Os resumos e programas deuteronomistas em Js 1; 23 e 11. 16-20 deixam entrever claramente que a situação territorial do reino davídico foi retrojetada para a época da tomada da terra: desde o começo Javé precisava ter destinado às tribos de Israel todo aquele grande território que Davi de fato dominava. A descrição da tomada da terra do livro de Josué legitima, portanto, uma reivindicação de território e de domínio que passageiramente fora realizada na era davídico-salomônica e depois disso permanecera viva como ideal.

Assim dá para entender que o relato das conquistas de terras realizadas na época de Josué na verdade refletem as conquistas que só ocorreram na época do rei Davi. Assim, a história da formação de Israel contida no livro de Josué foi relida por escritos oficiais para legitimar seus interesses de domínio sobre todo o território de Canaã. Citam-se então algumas destas releituras.

Na época do reinado de Davi. Conforme Gass (2011, p. 114), há possibilidade de haver uma primeira releitura do livro na época do monarca Davi, o qual unificou e dominou várias tribos israelitas e povos de culturas e origens diversas a partir de batalhas sangrentas. Era preciso legitimar seu império mostrando que Javé já havia dado toda aquela extensão de terra conquistada por ele desde as conquistas de Josué. Israel também precisava ser vista como uma única nação com consciência nacional e patriótica e com um poder centralizado na capital. Por isso Davi tinha muito interesse em contar as origens mais remotas do povo como uma conquista de um grupo homogêneo sob o comando de um único líder.

$\mathrm{Na}$ época do reinado de Ezequias. Conforme Gass (2011, p. 114) a época de Ezequias foi um contexto tão ou mais favorável ao surgimento ou releitura de escritos que narrassem a conquista sob um

Revista Pax Domini | Faculdade Boas Novas | vol. 1 | p. 143 - 157 | jul./dez. 2015 
único líder. Pois, uma vez aniquilado o Reino de Israel, foi na época de Ezequias que se procurou criar novamente uma consciência de unidade nacional, uma vez que muitos territórios haviam sido perdidos. Não só as terras das tribos do Norte estavam em poder dos assírios, mas também terras antes pertencentes à Judá.

$\mathrm{Na}$ época do reinado de Josias. Nesta época surge a chamada Obra Historiográfica Deuteronomística. ${ }^{6}$ Após o declínio da Assíria como potência internacional, houve um vazio de poder político internacional. Nesta época o rei Josias aproveitou para realizar suas reformas políticas e religiosas. "A obra tinha especialmente três finalidades: legitimar a destruição dos santuários de Israel, legitimar a centralização do culto no templo de Jerusalém e legitimar a extensão do poder da dinastia davídica também sobre as tribos do Norte. Estes são os elementos centrais da reforma de Josias" (GASS, 2011, p. 139).

O fato é que a intolerância e violência refletida no livro de Josué ocorrem nestes contextos citados acima em que o mesmo é relido. Conforme Dietrich (2013, p. 16-25) tanto o rei Davi como os reis Ezequias e Josias usaram de violência a partir de seus exércitos para fortalecer o monoteísmo centralizado em Jerusalém. Os mesmos se tornaram representantes de Javé dos exércitos, o Deus da arca. Assim Davi conquistou vários povos com suas guerras, e Ezequias e Josias com suas reformas proíbem cultos e oferendas fora de Jerusalém, sejam eles dedicados a outros deuses, às deusas, ou mesmo a Javé. A adoração passa a ser feita somente no templo em Jerusalém.

Dietrich (2013, p. 23) diz ainda que foi na época do rei Ezequias onde o rosto deste Javé oficial violento, excluidor, exclusivista, centralizador, homogeneizador e intolerante ficou gravado em muitas partes da Bíblia. Entende-se assim que apesar deste trabalho falar apenas do livro de Josué, há ainda outras passagens bíblicas que podem legitimar a intolerância religiosa apresentando Javé como um Deus que aprova atos de intolerância e violência.

Como ocorreu então a formação do povo Hebreu?

Uma leitura atenta do livro de Josué mostra que a verdadeira luta se deu contra reis e contra cidades e não contra a população. Os polos do conflito não são Israel contra Cananeus, mas sim campo contra cidade. De um lado o "campo", força produtora, geradora de riqueza, mas explorada, oprimida e

\footnotetext{
${ }^{6}$ Para uma melhor compreensão sobre a Obra Historiográfica Deuteronomista é sugerida aqui a leitura do texto em: SCHMIDT, Werner H. Introdução ao Antigo Testamento. Trad. Annemarie Hohn. - São Leopoldo: Sinodal, 1994, páginas $119-142$.
}

Revista Pax Domini | Faculdade Boas Novas | vol. 1 | p. 143 - 157 | jul./dez. 2015 
pobre; do outro lado, a "cidade", força exploradora, que se sustenta concentrando e comercializando a riqueza produzida pelo campo (GALLAZZI, 1988). O povo judeu nasce da resistência ao sistema opressor e tributário.

Esta também será a proposta mais defendida por Schwantes (2010, p. 11), Ceresko (1996, p. 101) e Gass (2011, p. 32) de que Israel se formou da desintegração da sociedade cananéia e do êxodo da população dos vales cananeus para as montanhas. Regiões desocupadas, especialmente das montanhas centrais de Canaã, foram ocupadas por camponeses e outros setores excluídos que se revoltaram contra os reis cananeus. Desta forma surge uma nova comunidade, um novo povo, os hebreus.

O termo "hapirus" que originou o termo "hebreu" na Bíblia, são pessoas com seus direitos limitados e de escassos recursos econômicos. Prestam serviço onde e quando são requisitados, como mercenários ou assalariados. "'Hapirus' ou hebreus são palavras que não indicam uma determinada etnia, nação ou raça, mas um grupo de mesma condição social. O que têm em comum é que são todos empobrecidos." (GASS, 2011, p. 35).

Gallazzi (1988, p. 17) chama a atenção para o fato de que o povo de Israel parecia ser um povo misturado, onde não havia apenas um “Israel puro", mas também quenitas (Nm 10. 29-32; Jz 4. 11, 17), Midianitas (Ex 2. 21), Cuxitas (etíopes e negros) (Nm 12. 1) e uma não bem identificada multidão que possuía gado e ovelhas (Ex 12. 38). Também o livro de Juízes fala de inumeráveis grupos que conviveram com os israelitas (Jz 1. 27-36). Assim é difícil afirmar que Javé seja o mesmo Deus de uma nação em sentido estrito.

\section{CONCLUSÃO}

A pesquisa deixa claro que não há como negar a influencia dos textos bíblicos para a intolerância, porém, esta influencia se dá pelos escritos de linha oficial. Escritos que intentavam a proteção dos reis, sacerdotes dos palácios, comerciantes, juízes, entre outros, e excluíam a parte mais pobre e oprimida. Os escritos de linha popular refletem exatamente o contrário. O Deus que está com seu povo para promover a justiça, a paz e a vida.

É preciso haver uma interpretação mais crítica da Bíblia. Ler a Bíblia com princípios de libertação. Quando alguém se aproxima dos textos Bíblicos deve ter como critério que Deus deseja a paz, o amor, a tolerância, a comunhão, a solidariedade e o respeito. Deve-se suspeitar de textos que

Revista Pax Domini | Faculdade Boas Novas | vol. 1 | p. 143 - 157 | jul./dez. 2015 
mostram Javé como um Deus violento, intolerante e excludente, para que tais textos não venham gerar atos de intolerância.

O livro de Josué apesar de mostrar em uma primeira leitura uma invasão violenta do povo hebreu em Canaã, em que mata e expulsa o povo, vai mostrar na verdade que a real história da formação do povo hebreu em Canaã foi ofuscada pelas releituras que ocorreram durante a história do povo judeu. A formação na verdade se deu pela resistência do campesinato, que oprimido e explorado pelos reis das cidades cananitas se refugiaram nas montanhas formando uma nova comunidade.

\section{REFERÊNCIAS BIBLIOGRÁFICAS}

BRASIL. Secretaria de Direitos Humanos da Presidência da República. Diversidade religiosa e direitos humanos. $3^{\mathrm{a}}$ ed. Brasília: Editora União Planetária, 2013.

\section{CERESKO, Anthony R. Introdução ao Antigo Testamento numa perspectiva libertadora.}

Tradução: José Raimundo Vidigal - São Paulo: Paulus, 1996.

DIETRICH, Luiz José. Violências em nome de Deus: monoteísmo, diversidade e direitos humanos. São Leopoldo: CEBI, 2013.

DONNER, Herbert. História de Israel e dos povos vizinhos. Tradução de Claudio Molz e Hans Trein. - São Leopoldo: Sinodal, 1997.

DREHER, Carlos A. Josué: ¿modelo de conquistador? Revista de Interpretación Bíblica Latinoamericana - Biblia: 500 años: ¿conquista o inclusión? n. 12, 1992. Disponível em: <http://www.ribla.org>. Acesso em: 17 Jan. 2014.

GALLAZZI, Sandro. “Celebramos las justicias de Yavé”. Revista de Interpretación Bíblica Latinoamericana - Violencia poder y opresión. N. 2, 1988. Disponível em: 〈http://www.ribla.org>. Acesso em: 01 Mar. 2014.

Revista Pax Domini | Faculdade Boas Novas | vol. 1 | p. 143 - 157 | jul./dez. 2015 
PIXLEY, Jorge. A história de Israel a partir dos pobres. Petrópolis: Editora Vozes, 2004.

SCHMIDT, Werner H. Introdução ao Antigo Testamento. Trad. Annemarie Hohn. - São Leopoldo: Sinodal, 1994.

SCHWANTES, Milton. História de Israel: local e origens. 3. ed. alt. e ampl. - São Leopoldo: Oikos, 2008.

SILVA, Clemildo Anacleto da; RIBEIRO, Mário Bueno. Intolerância religiosa e direitos humanos: mapeamentos de intolerância. Porto Alegre: Sulina; Porto Alegre: Editora Universitária Metodista, 2007.

SILVA, Clemildo Anacleto. A importância do Comitê Nacional da Diversidade Religiosa no combate à intolerância. Anais do Congresso Internacional da Faculdades EST. São Leopoldo: EST, v. 1, 2012. |p. 1195-1209.

SMITH, Mark S. O memorial de Deus: história, memória e a experiência do divino no Antigo Israel. São Paulo: Paulus, 2006. 